\title{
Marcas de moda e a percepção dos consumidores
}

\section{Fashion brands and consumer perceptions}

\author{
ALVAREZ, Francisco J.S.M. I Dr. Administração \\ Universidade de São Paulo \\ falvarez@usp.br
}

\section{FAVERO, Marcela Bortotti I Mestrando em Têxtil e Moda}

Universidade de São Paulo

mar_favero@hotmail.com

\section{VIEIRA, Francisco Giovanni David I Pós-doutor Administração}

Universidade Estadual de Maringá

fgdvieira@yahoo.com

\begin{abstract}
Resumo
O presente trabalho concentra-se no objetivo de identificar a percepção dos consumidores quanto às propagandas impressas, do setor de vestuário de moda, abordando as variáveis de: lembrança de marca, de logomarca e da mensagem da propaganda. Notou-se que nomes curtos para marcas são mais facilmente recordados, que atributos como simplicidade e presença de cores fortes valorizam a logomarca e que imagens que transmitem emoções são

\section{Abstract}

This work focuses on the objective of identifying consumer perceptions regarding print advertising, the industry of fashion garments, addressing variables: brand awareness, the logo and the message of the advertisement. It was noted that short names for brands are more easily remembered, that attributes such as simplicity and the presence of strong colors value the logo and images that convey emotions are highlighted.
\end{abstract} mais destacadas.

Palavras Chave: Comunicação de marketing. Marcas de moda. Percepção dos consumidores. Propaganda impressa.

Keywords: Marketing communication. Fashion brands. Consumer perceptions. Print ads. 


\section{INTRODUC̣̃̃O}

O setor têxtil no Brasil conta com 30 mil empresas e emprega aproximadamente 1,5 milhões de trabalhadores, sendo responsável por 13\% do PIB nacional (ASSOCIAÇÃO BRASILEIRA DA INDÚSTRIA TÊXTIL, 2011). O país é o quinto produtor têxtil do mundo, tendo em 2010 um faturamento de US $\$ 60,5$ bilhões. A expansão do setor é um grande atrativo para as novas empresas, que se inserem com facilidade, o que sugere o grande percentual de micro e pequenas empresas (70\%) na composição da indústria brasileira do vestuário em 2008 (ABIT, 2011). O setor apresenta inúmeras empresas oferecendo produtos para um mesmo público, o que caracteriza um mercado com forte concorrência, em especial quando se trata da moda para o mercado de massa, ou como é comumente chamada, a "modinha". Modinha é a cópia que se dá a partir de referências dos desfiles, da televisão e de revistas, mesmo que com algumas adições ou alterações de detalhes (AVELAR, 2009).

Com o setor fortemente aquecido economicamente, e também extremamente competitivo, o desenvolvimento dos produtos ultrapassou a barreira prático-funcional. Hoje, as confecções buscam comercializar sentimentos, memórias e experiências através do desenvolvimento das características estético-simbólicas ( $L O B A C H, 2001)$, como confirmado por Lipovetsky e Machado (2007, p. 8) quando ponderam que o desejo de moda "ultrapassou a esfera da indumentária".

Tal contexto define a importância da construção e consolidação das marcas no mercado de moda. A marca é um símbolo, nome, referência ou identidade de um produto ou linha de produtos para o consumidor (URDAN; URDAN, 2006), e sua existência faz sentido diante de um mercado competitivo onde a organização corre risco de perder seus consumidores devido a grande gama de produtos similares em termos de qualidade e design.

Os laços são desenvolvidos pela gestão de marketing possibilitando o estreitamento das relações com o público-alvo. Nesse sentido, atua como um canal entre os valores/conceitos da marca e os sentimentos despertados no consumidor. Uma das ferramentas do composto de marketing mais utilizada, para atrair e conquistar o consumidor, é a propaganda. A propaganda é definida como toda forma paga de comunicação impessoal sobre uma organização, produto, serviço ou idéia; envolve normalmente a mídia de massa - televisão, revistas, jornais, rádio, entre outras (BELCH; $B E L C H, 2008)$. Assim, considerase propaganda impressa àquela realizada junto a outdoors, revistas, jornais, catálogos, enfim, realizada nos meios impressos. Diante desse panorama, o artigo concentra-se no objetivo de identificar a percepção dos consumidores quanto aos fatores que compõem as propagandas impressas, no setor de 
vestuário de moda.

\section{Marcas e representações simbólicas}

Nos últimos anos, em razão da alta competitividade entre as organizações, percebeu-se que os ativos tangíveis do produto, como cor, tamanho, forma, valor monetário, entre outros estão se tornando obsoletos rapidamente, devido em especial, ao avanço tecnológico e a facilidade de reprodução. Com isso, ganham notoriedade os ativos intangíveis, como status e imagem transmitida, de maneira que se destaca a marca, já que está intimamente relacionada aos benefícios percebidos pelo consumidor (CAPUTO; MACEDO; NOGUEIRA, 2008; FERREIRA, 2006).

Entende-se que marca é uma representação simbólica de uma organização constituída por meio de um nome, uma imagem, um símbolo que dá origem ao logotipo ou logomarca. A imagem da marca pode ser entendida como o campo simbólico compartilhado sobre esta (NOBERTO, 2004), destacando-se a partir do momento que as mediações sociais são influenciadas cada vez mais pela sua comunicação e seus símbolos (RIEGEL, 2010).

Em referência à moda e à indústria do vestuário, considera-se que o poder da marca está no equilíbrio da criatividade do estilista e das ações de marketing (TUNGATE, 2008). Sua importância se destaca quando os consumidores passam a requerer elementos que transcendem a sua grife (CHAMMA; PASTORELO, 2007), que é o caso das qualidades extrínsecas do produto. Grandes marcas não vendem apenas objetos bonitos e com qualidade, vendem histórias e um estilo de vida; quanto mais convincente é a história mais atrativa se torna a marca (TUNGATE, 2008; ROBERTS, 2005).

Cada marca é posicionada no mercado através de determinado conceito, e essa prática de posicionamento desempenha "um papel fundamental no marketing moderno, sugerindo ao cliente maneiras pelas quais a empresa se difere dos concorrentes atuais e potenciais" (FURRIER, 2008, p. 164). O posicionamento da marca é uma estratégia que permite a externalização da identidade desta, que reflete na imagem da marca construída na mente do consumidor. Sendo que a identidade e o conceito da marca nada mais são que um conjunto de características/atributos que configuram sua personalidade (AAKER, 2000).

A identidade de marca pode ser tanto de caráter visual quanto verbal. A identidade visual consiste nos componentes gráficos, como logotipos, 
símbolos, cores. Já a identidade verbal é constituída pelo nome da marca, uma assinatura ou uso de histórias (KHAUAJA, 2008). Enfim, a identidade da marca "representa seus valores, sua substância, que está presente nas suas falas e nos seus elementos visuais" (RIEGEL, 2010, p. 132).

\section{Comunicação de Marketing}

Os consumidores se deparam com um cenário de inúmeros produtos similares, em especial no mercado da moda, e um bombardeio de mensagens publicitárias, o que dificulta a escolha por uma marca ou outra. Assim, a ferramenta de comunicação de marketing ganha destaque, com a principal função de dar um motivo ao consumidor para comprar a marca (EASY, 2009; ZENONE; BUAIRIDE, 2005; CIFUENTES; BARRERO; MEDONZA, 2006). Para Martins (1992, p. vii) a comunicação de uma marca tem duas funções, "uma é mostrar de maneira clara os benefícios do produto, e a outra é criar uma aura de encantamento".

Martins (1992) complementa que o consumidor é mobilizado pela emoção, que possui o significado para a escolha de uma marca. A essência do marketing consiste nessa descoberta do "espírito do produto", que permite a criação do elo emocional entre marca e consumidor, estabelecendo uma relação íntima e duradoura. Nesse contexto, o principal objetivo da estratégia de comunicação é desenvolver uma atitude favorável do consumidor em relação à marca.

Pinheiro e Gullo (2008) afirmam que a comunicação com o consumidor é realizada através de símbolos e signos, criando a mensagem que informará a respeito do produto. Isso significa dizer que a propaganda é constituída por imagens, tipologias, cores e texturas que viabilizam a comunicação de uma determinada mensagem ao consumidor. Após a decodificação da mensagem pelo público, tem-se a resposta ao anunciante, que se reflete na procura ou não pelo produto.

Uma das principais ferramentas do composto de comunicação é a propaganda, que tem como principal objetivo criar e fazer a manutenção da imagem da marca de um produto ou uma empresa, informando atributos, benefícios e a razão para o consumo. Os resultados da propaganda deveriam ser a obtenção da aceitação e preferência do consumidor, e a presença na sua mente (PINHEIRO; GULLO, 2008). Para Pride e Ferrel (1980) a propaganda tem a função de promover o produto e a organização, estimular diretamente a demanda para o consumo, tornar a venda pessoal mais efetiva, promover as diversas maneiras de uso do produto, relembrar e reforçar a imagem da marca 
na mente do consumidor e reduzir as flutuações da demanda.

Dentro da indústria da moda, os principais tipos de propaganda são: comerciais televisivos, outdoors e anúncios em revistas, em especial pelo uso de imagens. A revista apresenta-se como o veículo de fácil segmentação, o que o torna atrativo, pois permite à marca encontrar um canal com um público leitor similar ao seu público alvo, tornando seu investimento em marketing mais eficaz (EASEY, 2009).

Ao elaborar uma propaganda deve-se atentar para a estrutura da mensagem e a seleção de mídia (URDAN; URDAN, 2006). A primeira corresponde à "maneira que está composta para conseguir o melhor efeito sobre o receptor" (URDAN; URDAN, 2006, p. 258). É definida a partir da quantidade e repetição das informações, contudo, ressalta-se que estas não devem ser excessivas, devido à dificuldade do receptor em processar grandes quantidades de informações. A mensagem de uma propaganda pode ser transmitida de inúmeras maneiras, sendo uma das mais eficientes o uso da imagem, a qual tem uma enorme influência no processo de construção da marca, já que traduz a marcaem um conceito, trazendo a marca para a vida (TUNGATE, 2008; MARTINS, 1992).

A imagem tem três dimensões a serem trabalhadas: funcional, conceitual e emocional (MARTINS, 1992). A dimensão funcional trata das necessidades funcionais do produto, evidenciando as características que o consumidor deseja objetivamente, relacionadas ao seu desempenho. A dimensão conceitual referese aos conceitos criados a respeito dos produtos e das marcas, que muitas vezes podem não ser verdadeiros. E a dimensão emocional é a que tem o maior poder de gerar resultado, é "o sentimento positivo construído através da imagem que faz com que o consumidor pague mais" (MARTINS, 1992, p. 2).

Portanto, foram apurados na pesquisa os temas de comunicação de marcas de moda. Para tanto, abordaram-se os conceitos de: marcas, propaganda impressa (elementos de composição), identidade visual e mídia.

\section{METODOLOGIA}

A pesquisa desenvolvida caracterizou-se como exploratória, visto que buscou a familiarização com o fenômeno (AAKER; KUMAR; DAY, 2004), e teve por objetivo identificar a percepção dos consumidores quanto aos fatores que compõem as propagandas impressas no setor de confecções e moda. A coleta de dados primários foi realizada por meio do uso de questionário estruturado 
junto ao público-alvo. Este abordou um estudo das variáveis descritas no quadro 1, definidas a partir do referencial teórico construído para este estudo e já apresentado na seção anterior.

Quadro 1 - Variáveis estudadas na pesquisa.

\begin{tabular}{|l|l|}
\hline \multicolumn{1}{|c|}{ Variável } & \multicolumn{1}{c|}{ Objetivo } \\
\hline 1- Marcas & Identificar as marcas de confecção mais lembradas \\
\hline 2- Lembrança de logomarca & Verificar a lembrança ou não de logomarcas de confecções \\
\hline 3- Atributos da logomarca & Enumerar os atributos que chamam a atenção na logomarca \\
\hline 4- Imagem & Escolha de uma imagem entre as 6 propostas \\
\hline 5- Motivo de escolha & Razão da escolha daquela imagem \\
\hline 6- Mídia & Identificar os meios impressos em que mais existe lembrança de \\
propagandas de moda.
\end{tabular}

Fonte: Elaborada pela autora a partir da pesquisa Fonte bibliográfica, 2011.

Para a variável de número quatro, foram selecionadas seis imagens de propagandas impressas de vestuário de moda, de marcas nacionais e internacionais. As imagens foram escolhidas de acordo com os apelos de marketing apresentados, como o destaque de modelo/produto e/ou conceito da peça publicitária por meio do humor, sensualidade ou crítica, entre outros fatores, sendo todos comumente usados no universo da confecção. Ressalta-se que a identificação da marca dos produtos foi retirada da propaganda devido ao viés que a presença da mesma poderia causar para a pesquisa. 
Tabela 1 - Imagens selecionadas $\mathrm{x}$ motivo

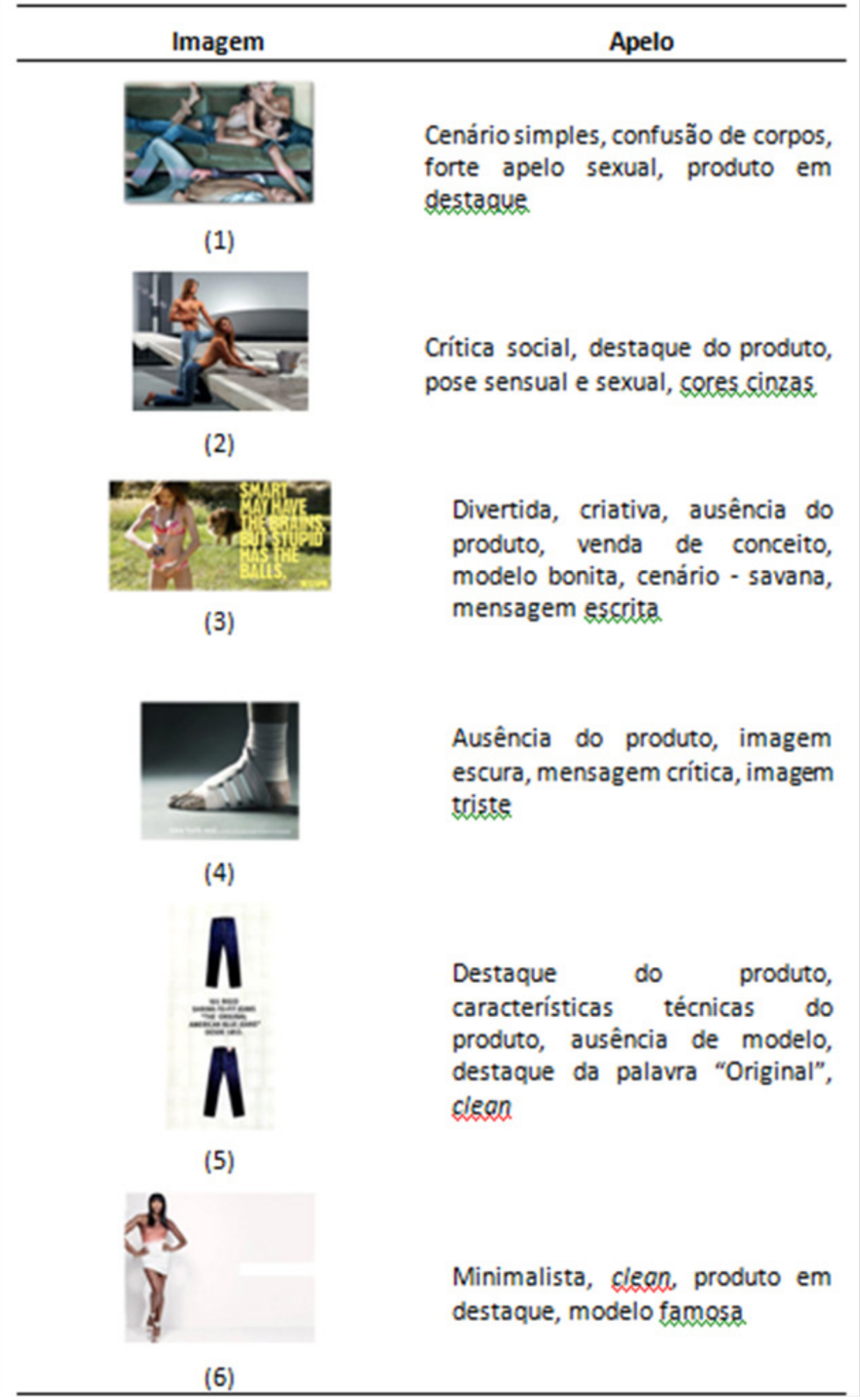

Fonte: Pesquisa de Campo (2011). 
Devido aos resultados do piloto, onde se observou uma baixa lembrança de propagandas por parte das classes $\mathrm{D}$ e E, classificadas de acordo com o critério Brasil, estas foram excluídas da pesquisa. Além disso, a classe A também foi excluída da amostra devido à dificuldade de acesso da pesquisadora a estes indivíduos.

Com isso, a amostra foi composta por 120 indivíduos, e o procedimento de amostragem caracterizou-se como não-probabilístico e por conveniência. Do total de entrevistados, tem-se $51,7 \%$ de indivíduos do gênero feminino e $48,3 \%$ do gênero masculino. Estes se encontraram divididos nas seguintes faixas de idade: (1) 18- 24 anos (19,2\%), (2) 25 - 34 anos (24,2\%), (3) 35 - 39 anos (11,7\%), (4) 40 - 49 anos (20\%), (5) 50 -59 anos (11,7\%), (6) acima de 60 anos $(13,3 \%)$.

A tabulação dos dados do questionário foi realizada usando o software Le Sphinix Plus v 4.5. Os resultados das perguntas abertas foram agrupados como resultado da análise semântica quantitativa, de maneira que as análises são de caráter estatístico descritivo, pautadas em relatórios de pesquisa univariados e bivariados.

\section{ANÁLISE DOS RESULTADOS}

A análise de resultados está dividida em três blocos. Primeiramente, discute-se acerca da marca e lembrança desta. Em seguida, dialoga-se sobre a identidade visual da marca, em especial, sobre a logomarca. O terceiro ponto aborda a temática das imagens apresentadas na pesquisa, neste momento procura-se entender os motivos pelos quais os consumidores escolheram determinadas imagens. E por fim, sobre as mídias destacadas na pesquisa.

\section{Marcas}

Foram identificadas, primeiramente, as marcas mais lembradas, sendo estas: Nike (5,7\%), Colcci (5,4\%), Hering (5,1\%), Tommy Hilfinger (5,1\%), Levis $(4,4 \%)$, Lacoste (4,4\%), Adidas (4,1\%), Ellus (3,5\%), Forum (3,5\%), Pura Mania $(3,5 \%)$, For Boys e For Girls (2,8\%). Outras marcas foram citadas de maneira fragmentada perfazendo um total de $27,3 \%$. Foi possível perceber que todos os entrevistados souberam nomear de imediato duas ou mais marcas de vestuário de moda, o que demonstra que essas conseguem desenvolver suas imagens diante do público consumidor. Consequentemente, pode-se afirmar que as 
marcas estão cumprindo seu papel básico, que é identificar os produtos e, se possível, diferenciá-los dos concorrentes (CROCCO; TELLES; GIOIA, 2006; URDAN; URDAN, 2006).

Em um estudo direcionado às marcas, mais especificamente ao nome destas, nota-se a grande presença de nomes simples e curtos, que de acordo com Chamma e Pastorelo (2007), facilitam a memorização. Nota-se que das marcas mais lembradas 38,1\% são marcas internacionais, além disso, inúmeras marcas brasileiras também assumem o nome em outro idioma (em especial o inglês). Esse ponto nos leva a refletir sobre a valorização da marca internacional neste setor.

\section{Identidade visual (lembrança de logomarca e atributos da logomarca)}

A logomarca é a expressão gráfica da marca, constitui parte da identidade visual desta (KHAUAJA, 2008). Em relação a esta variável, observou-se que a maioria dos entrevistados (85,7\%) lembra-se de alguma logomarca de artigos de vestuário de moda. Dentre as lembranças alguns atributos se destacam fortemente, como as cores e a forma.

Quando se analisa as cores tem-se um leque muito grande de particularidades. Foram agrupados nesse bloco: cores vibrantes, presença de poucas cores, preto e branco, cores com contorno da imagem forte; porém o que mais se destacou foi a presença de cores fortes na logomarca (21\%).

Para a composição do grupo forma, considerou-se forma (formato) e desenho da logomarca. Dentro da análise da tipografia, agrupou-se: letras simples e/ou arredondada (15\%), letra colorida (5\%) e letra rebuscada (5\%). Com isso nota-se que a escolha da tipografia da logomarca não apresenta uma regra definida, sendo que as preferências variam de acordo com o público-alvo almejado.

Conclui-se, desse modo, que a logomarca deve ser uma simples associação entre o nome da marca (logotipo) e o símbolo que facilite a assimilação, memorização e lembrança, conforme apontado pela literatura. Observa-se que deve (a) ser trabalhada em cores fortes e (b) expressar, de uma maneira criativa, a identidade da marca, que consiste em seus valores e substâncias, conforme indicado por Riegel (2010). Os resultados também possibilitaram identificar a importância que os consumidores atribuem quanto aos valores de credibilidade e tradição (constância da logomarca). 
A lembrança de logomarca destaca-se ainda entre os indivíduos com até 50 anos (Tabela 2), sendo que só a partir dessa idade o percentual de lembrança é inferior a $87 \%$ dos entrevistados, conforme segue abaixo. Esse fato pode estar relacionado às gerações e ao acesso às informações que cada grupo de idade teve ao longo de sua trajetória. Sabe-se que os mais novos cresceram em contato com a internet e com um acesso muito amplo a informações. Além disso, a grande quantidade de informações estimula a valorização das marcas, aumentando assim o reconhecimento dessas, o que pode influenciar no aumento da lembrança da logomarca. Na mesma linha de pensamento, a dinâmica de mercado das últimas décadas expõe o consumidor a uma gama alta de marcas novas todos os dias. Ter uma marca é como ter um apoio, um sinal de continuidade, uma certeza (ROBERTS, 2005), algo em que o consumidor confia e acredita.

Tabela 2 - Lembrança de logomarca x faixa etária

Tabela 2 - LEMBRANÇA DE LOGOMARCA X FAIXA ETÁRIA

\begin{tabular}{l|lll}
\hline \multirow{2}{*}{ Faixas Etárias } & \multicolumn{3}{l}{ Lembrança } \\
\cline { 2 - 4 } & Sim (\%) & Não (\%) & Total (\%) \\
\hline $18-24$ anos & 87 & 13 & 100 \\
$25-34$ anos & 96,6 & 3,4 & 100 \\
$35-39$ anos & 92,3 & 7,7 & 100 \\
$40-49$ anos & 91,7 & 8,3 & 100 \\
$50-59$ anos & 64,3 & 35,7 & 100 \\
Acima de 60 anos & 68,8 & 31,3 & 100 \\
\hline
\end{tabular}

Fonte: Pesquisa de Campo, 2011.

Quando se aborda os atributos da logomarca, percebe-se que somente as mulheres valorizam atributos como a identidade e a tradição. Já, em relação à simplicidade, observa-se que $63,2 \%$ dos que atentam-se a esse atributo são do gênero masculino. Isso permite apontar que os homens parecem não se importar com as mudanças na logomarca e nem com os signos que remetam a identidade da marca. Para eles é fundamental que a logo seja clara, simples, facilitando a memorização.

Ao contrário, a mulher tem na logomarca da empresa um sinal de referência, não importando a complexidade da logomarca e a infinidade de elementos que ela pode conter. Para as mulheres o caráter de atemporalidade da logomarca é importante. Além disso, é fundamental para elas que a logomarca se relacione com a identidade da marca, criando uma espécie de laço: marca-identidade 
visual - consumidor.

Analisando as faixas etárias observa-se que os mais novos prestam atenção em elementos gráficos, como cores, tipografia e imagens. Por outro lado, os pertencentes aos grupos de idade acima de 50 anos valorizam mais os aspectos intrínsecos da logomarca, ou seja, seus significados simbólicos, como tradição e identidade. Reforçando assim as características das gerações como indicado anteriormente.

Notou-se ainda que os entrevistados que recordam de logomarcas normalmente costumam ver propagandas impressas em revistas $(29,7 \%)$, e os que não têm lembrança de logomarcas normalmente veem propaganda impressa em outdoors (52,9\%). Sendo que, conforme já apontado, na opção "outros" tem-se a presença da internet. Assim, pode-se afirmar que para o posicionamento da logomarca na mente do usuário é mais interessante a utilização de propagandas impressas em revistas.

Quando se pensa nos atributos da logomarca em relação à mídia em que a propaganda é veiculada, têm-se: (a) para o outdoor a necessidade de logomarcas que se destaquem, pelas cores, identidade e criatividade. Devido ao tempo que o usuário normalmente tem para contemplar um outdoor, torna-se extremamente fundamental, como demonstrou também a pesquisa, a simplicidade da logomarca. (b) Atributos que carregam mais significados, como a tradição, já se destacam em mídias nas quais o usuário pode observar com mais tempo, como catálogos e revistas. Isso se justifica nas palavras de Easey (2009), colocando que o outdoor deve ser simples e conter poucas informações, para que os consumidores não percam a atenção.

\section{Imagem (motivo de escolha das imagens)}

Os autores Turgate (2008) e Martins (1992) colocam a imagem como uma das formas mais eficientes de transmitir a mensagem de determinada propaganda, isto porque esta traz, por si própria, conceito e vida para a marca. Como descrito na metodologia, o entrevistado foi exposto a seis propagandas impressas de confecções, que tinham apelos diferentes.

Dentre as seis figuras propostas notou-se que as mulheres apresentam forte preferência pela imagem $1(u m)(30,6 \%)$, caracterizada por um apelo sexual mais forte, apresenta uma iluminação mais baixa e inúmeros modelos. Já os homens apresentam atenção a imagem 3(três) (27,6\%), que é uma imagem composta por um cenário africano, uma modelo bonita com lingerie 
e ainda uma frase de humor. Acredita-se que os homens foram atraídos pela modelo bonita, visto que quando analisamos o motivo da escolha da imagem e o gênero, observamos que os homens (52,9\%) consideram os modelos como um destaque da imagem em relação a opinião das mulheres.

É relevante observar ainda, que nenhuma das entrevistadas indicou a imagem 5 (cinco), que é uma exposição clara da peça sem modelo, como uma propaganda que the chama a atenção. Esta mesma imagem prendeu a atenção de 12,1\% dos homens. Essa situação é esclarecida pelos fatores comportamentais dos gêneros, onde os homens são mais práticos, funcionais e diretos. Fato o qual é confirmado ainda, quando se analisa as razões da escolha da imagem em relação ao gênero e aponta-se que dentre o caráter de simplicidade, a preferência dos homens destaca-se $(63,6 \%)$, afirmando assim, o gosto por coisas diretas, funcionais e práticas.

Diante de uma perspectiva de grupos de idade, têm-se: de 18 a 49 anos a preferência pela imagem 1 (um), que apresenta um contraponto interessante que é o total descaso em relação a essa imagem aos maiores de 50 anos. Essa imagem apresentou características citadas pelos entrevistados como sensualidade, sexualidade e apelativa; pontos os quais não foram colocados pelos de idade mais avançada. Isso permite entender que o público consumidor pertencente às faixas de idade mais elevada preferem propagandas mais brandas, que não apresentem um apelo sexual forte, para o consumo de roupa. Essa preferência possivelmente está ligada com a fase em que esses se encontram do ciclo da vida, experiências acumuladas, entre outros fatores que compõe os fatores pessoais do consumidor (KOTLER; ARMSTRONG, 1993). Como resultado disso, para o grupo acima de 60 anos, a imagem que mais chama a atenção é a número 6 (seis), que é uma imagem mais clean, que apresenta o produto com clareza.

Observa-se que as mídias que mais são lembradas associadas com as imagens são as revistas e os outdoors. Sendo que o outdoor é ainda a mídia mais impactante quando associada à análise de todas as imagens. Um destaque particular se dá a essa mídia quando se analisa o caso da imagem número 5 (cinco), em que 57,1\% dos entrevistados colocaram que normalmente vêem a propaganda impressa no outdoor. Vale lembrar que essa imagem só chamou a atenção de homens, como exposto acima.

Apenas 3,4\% dos entrevistados que apresentaram preferência pela imagem 3 (três), colocaram a mala-direta como uma mídia expressiva. As baixas associações das imagens com a mala-direta nos permite concluir que estas, normalmente, não trazem propagandas que chamam a atenção ao ponto de ficarem armazenadas na memória dos entrevistados. 
Ao olhar mais especificadamente para a mídia "revistas", nota-se que: (a) $50 \%$ das pessoas que colocaram a imagem 6 (seis) como a que mais chama a atenção e optaram pela mídia revista, apresentam como veículo a "Revista Caras". Uma revista que tem como conteúdo o cotidiano das celebridades, lembrando que a imagem 6 (seis) é a que apresenta a modelo famosa Naomi Campel; (b) Os homens em sua maioria preferem a revista "Veja". O fato se consolida ao analisar a preferência das revisa quando se trata da analise da imagem 5 (cinco), que só foi apontada por homens, onde 66,7\% vêem normalmente as propagandas impressas na revista Veja.

\section{Mídia}

A pesquisa permitiu também identificar a mídia em que normalmente as propagandas impressas são vistas, a saber: outdoor, revista, encartes, catálogos, jornal, mala-direta, entre outros. Observa-se que grande parte dos entrevistados se lembra de ter visto propaganda de vestuário em outdoors (47,1\%), seguido de revistas, com $27,7 \%$ das respostas. Como outros meios, foi citada apenas a internet, neste caso considerado impressa em virtude da possibilidade do leitor imprimir os arquivos eletrônicos.

Observa-se que as mídias que mais são lembradas e associadas com as imagens são as revistas e os outdoors. Sendo que o outdoor é ainda a mídia mais impactante quando associada à analise de todas as imagens. Um destaque particular se dá a essa mídia quando se analisa o caso da imagem número 05, onde 57,1\% dos entrevistados mencionaram que normalmente veem a propaganda impressa no outdoor. Vale lembrar que essa imagem só chamou a atenção de homens, como exposto acima.

Com relação à revista, considera-se que é a mais efetiva, uma vez que permite uma segmentação mais fácil, tornando o investimento mais eficaz (EASEY, 2009). As revistas que foram apontadas pelos entrevistados foram: Veja (33,3\%), Caras (18,2\%), Manequim (9,1\%), Cláudia, Istoé e Nova (6,1\% cada), Contigo, Elle, Época, Marie Claire, Quatro Rodas e Vogue (3,0\% cada).

Ao olhar mais especificadamente para a mídia "revistas", nota-se que: (a) $50 \%$ das pessoas que indicaram a imagem 06 como a que mais chama a atenção e optaram pela mídia revista, apresentam como veículo a "revista Caras". Uma revista que tem como conteúdo o cotidiano das celebridades, lembrando que a imagem 6 é a que apresenta a modelo famosa Naomi Campel; (b) Os homens em sua maioria preferem a revista Veja. O fato se consolida ao analisar a preferência das revisa quando se trata da analise da imagem 5 (que 
só foi apontada por homens), onde $66,7 \%$ veem normalmente as propagandas impressas na revista $\vee$ eja.

Vale notar o baixo percentual da mídia mala-direta. Esta é colocada por Bergström (2009) como a "mais odiada" pelos consumidores. Porém, os anunciantes ainda a vêem como uma forte ferramenta de comunicação, pois é um meio seletivo e flexível.

Apenas 3,4\% dos entrevistados que apresentaram preferência pela imagem 03, indicaram a mala-direta como uma mídia expressiva. As baixas associações das imagens com a mala-direta nos permite concluir que estas, normalmente, não trazem propagandas que chamam a atenção ao ponto de ficarem armazenadas na memória dos entrevistados.

\section{CONCLUSÃO}

Diante do objetivo proposto para este artigo, que buscou identificar as percepções dos consumidores quanto às marcas, logomarcas e propagandas impressas de confecções, subdividiu-se o tópico da conclusão. O quadro abaixo apresenta uma síntese de todos os resultados apresentados e discutidos.

Quadro 2 - Resumo dos resultados.

\begin{tabular}{|l|l|}
\hline \multicolumn{1}{|c|}{ Variável } & \multicolumn{1}{|c|}{ Objetivo } \\
\hline Marcas & $\begin{array}{l}\text { - todos os entrevistados conseguiram recordar nomes de marcas } \\
\text { de confeç̧ões; } \\
\text { - nomes curtos são mais fáceis de memorizar; } \\
\text { - valorização de nomes em grafia estrangeira. }\end{array}$ \\
\hline Identidade Visual & $\begin{array}{l}\text { - deve proporcionar uma simples associação entre o nome e o } \\
\text { símbolo; } \\
\text { - (a) ter caráter delicado, suave e discreto, (b) ser trabalhada em } \\
\text { cores fortes e (c) expressar, de uma maneira criativa, a } \\
\text { identidade da marca, que consiste em seus valores e } \\
\text { substâncias. }\end{array}$ \\
\hline Imagem & $\begin{array}{l}\text { - destaque para a imagem de número } 3 \text { (Diesel) - não faz alusão } \\
\text { apenas a dimensão funcional do produto; } \\
\text { - destaque também para propagandas cleans. }\end{array}$ \\
\hline Mídia & $\begin{array}{l}\text { - destaque para revista e outdoor, ressaltando que a revista por } \\
\text { permitir que o consumir desfrute mais tempo com a propaganda } \\
\text { facilita a promoção de mensagens. }\end{array}$ \\
\hline
\end{tabular}

Fonte: Elaborado pelos autores, 2011.

No que tange ao assunto marcas, observou-se o destaque dos nomes curtos e a forte presença de marcas/nomes internacionais na memória do 
entrevistado. Com isso, pode-se afirmar, conforme previsto pela literatura, a facilidade de memorização de nomes curtos. E ainda, observa-se que o consumidor brasileiro atenta-se fortemente a marcas internacionais (ou as que têm nomes estrangeiros), o que pode estar relacionado com a impressão de que os artigos de qualidade são em geral importados, além de sugerir uma associação de produtos importados com status, luxo.

Em relação à logomarca destaca-se a simplicidade, com presença de cores fortes. Vale observar, nesse sentido, que a tradição é alcançada pela constância da logomarca, ou seja, uma logomarca que acompanha o desenvolvimento da marca sem sofrer alterações gráficas freqüentemente.

Pela análise das imagens pode-se observar que os consumidores são atraídos por propagandas que evidenciem valores, comportamentos e experiências, e não o produto por si só. Ou seja, embora seja importante a presença do produto na propaganda impressa, a criatividade, o caráter inusitado e o humor são fatores que merecem destaque.

Sobre as propagandas impressas, vale evidenciar a forte lembrança quanto ao outdoor como mídia. Neste ponto destaca-se que o outdoor é uma mídia onde o maior objetivo deve ser a divulgação de marca, contendo propagandas com poucas informações e cores de destaque. Por outro lado, na revista a comunicação pode ser mais detalhada, possibilitando ao anunciante colocar um maior número de detalhes, o que permite que a marca seja lembrada pelo consumidor, estreitando assim o relacionamento.

Por se tratar de pesquisa exploratória as conclusões não são válidas para todo o universo de marcas de moda, mas o estudo contribui para o conhecimento e pode ser utilizado como base para estimular novas pesquisas em percepções dos consumidores quando à propaganda. 


\section{REFERÊNCIAS}

AAKER, D. A. Como construir marcas líderes. São Paulo: Futura, 2000.

AAKER, D. A.; KUMAR, V.; DAY, G. S. Pesquisa de Marketing. 2. ed. São Paulo: Atlas, 2004.

ASSOCIAÇÃO BRASILEIRA DA INDÚSTRIA TÊXTIL. ABIT. Indústria têxtil e de confecção. Revista ABIT/TEXBRASIL. Disponível em: <www. abit.org.br>. Acesso em: 14 maio 2011.

AVELAR, S. Moda: globalização e novas tecnologias. São Paulo: Estação das Letras e Cores, 2009.

BELCH, G. E.; BELCH, M. A. Propaganda e promoção. 7. ed. São Paulo: McGraw-Hill, 2008.

Bergström (2009 - falta referencia...completar dados

CAPUTO, É. S.; MACEDO, M. A. S.; NOGUEIRA, H. G. P. Avaliação de marcas: uma aplicação do caso Bombril. RAE Eletrônica - Revista de Administração de Empresas Eletrônica, São Paulo, v. 7, n. 2, jul./dez. 2008.

CHAMMA, N.; PASTORELO, P. D. Marcas e sinalização. São Paulo: Senac, 2007.

CIFUENTES, C. A.; BARRERO, L. M. R.; MENDONZA, D. F. R.

Construcción de marcas, una forma de competir. INNOVAR - Espacio estudantil, v. 16, n. 27, 2006.

CROCCO, L.; TELLES, R.; GIOIA, R. M. (Coord.). Decisões de marketing: os 4 Ps. São Paulo: Saraiva, 2006.

EASEY, M. Fashion marketing. London: Wiley-Blackwell, 2009.

FERREIRA, A. L. B. Marketing cultural na construção das marcas: a percepção do público de Santa Cruz do Sul. 2006. Monografia (Graduação em Comunicação Social) - Universidade de Santa do Cruz Sul, Santa Cruz do Sul.

FURRIER, M. T. Patrimônio de marca. In: SERRALVO, F. A. (Org.). Gestão de marcas no contexto brasileiro. São Paulo: Saravia, 2008. p. 133-162. 
KHAUAJA, D. Construção de marcas. In: SERRALVO, F. A. (Org.). Gestão de marcas no contexto brasileiro. São Paulo: Saravia, 2008. p. p. 77-131.

KOTLER, Philip; ARMSTRONG, Gary. Princípios de marketing. 5. ed. Rio de Janeiro: Prentice-Hall do Brasil, 1993.

LIPOVETSKY, G.; MACHADO, M. L. A felicidade paradoxal: ensaio sobre a sociedade de hiperconsumo. São Paulo: Companhia das Letras, 2007.

LOBACH, B. Design industrial: bases para a configuração dos produtos. São Paulo: EdgardBlücher, 2001.

MARTINS, J. S. O poder da imagem: uso estratégico das emoções criando valor para a marca através da imagem. São Paulo: Makron Books, 1992.

NOBERTO, E. Estratégias corporativas de marcas e estratégias sociais de diferenciação: uma análise a partir do automóvel. Tempo Social revista de sociologia da USP, São Paulo, v. 16, n. 2, p. 203-208, 2004. Disponível em: <http://www.scielo.br/pdf/ts/v16n2/v16n2a09.pdf>. Acesso em: 12 jun. 2011.

OGDEN, J. R. Comunicação integrada de marketing: modelo prático para um plano criativo e inovador. São Paulo: Prentice Hall, 2002.

PINHEIRO, D.; GULLO, J. Comunicação integrada de marketing. São Paulo: Atlas, 2008.

PRIDE, W. M.; FERRELL, O. C. Basic concepts and decisions. 2. ed. Boston: Houghton Mifflin, 1980.

RIEGEL, V. Espacio de consumo provilegiado: el território de comunicácion publicitaria de la marca global. Pensar la publicidade, v. 4, n. 1, p. 129146, 2010. Disponível em: <http://revistas.ucm.es/inf/18878598/ articulos/PEPU1010120129A.PDF>. Acesso em: 12 jun. 2011.

ROBERTS, K. O futuro além das marcas: lovemarks. São Paulo: M Books, 2005.

TUNGATE, M. Fashion brands: branding style from Armani to Zara. 2. ed. London: Kogan Page, 2008.

URDAN, F. T.; URDAN, A. T. Gestão do composto de marketing. São Paulo: Atlas, 2006. 
ZENONE, L. C.; BUAIRIDE, A. M. R. Marketing da promoção e merchandising: conceitos e estratégias para ações bem-sucedidas. São Paulo: Cengage Leraning, 2005.

Recebido em: 29/11/2012.

Aceito em:11/03/2013. 